\title{
Phytochemicals and plant growth inhibitory activity of Ageratum conyzoides L. leaves
}

\author{
Rajesh Kumar Chawla ${ }^{1}$, Anil Boora ${ }^{2}$, Rajvir Singh ${ }^{3}$, Sumona Kumari ${ }^{4}$ and \\ S. B. Kalidhar ${ }^{5}$ \\ 1,2,3,4,5 Department of Chemistry, CCS Haryana Agricultural University, Hisar-125004, India.
}

\begin{abstract}
Ageratum conyzoides leaves have afforded six compounds which were identified as tritriacontane, henitriacontane, 23-pentatetraacontanone, 3,4,-seco-lup- 20 (29)-en-3-OMe, $3^{\circ}$ butyl triacosanoate and methyl tetracosanoate. All are being reported first time from this plant. The different fractions viz. hexane, benzene, ethyl acetate and methanol Ageratum conyzoides leaves were tested for their plant growth inhibitory activity against germination of radish seeds. The percent growth inhibition of radish seeds by different fractions are being reported in this paper.
\end{abstract}

Key words: Leaves, Ageratum conyzoides, Chromatography, IR, ${ }^{l} H N M R$

\section{Introduction}

The use of botanicals for the control of insects, pests and weeds has recently advanced to a new stage. The recent frontier has moved from study of synthetic chemicals to study of the thousands of phytochemicals that may have important physiological effects. There is a broad and growing consensus that many phytochemicals found may provide a plant protection umbrella to the crops and versatile protection for human beings . Natural plant products are easily degradable, less persistent in the environment and eco-friendly. The search of plant products is unanimous choice to manage different diseases and to control the development of several herbaceous plants or weeds. Ageratum conyzoides L. (Family Asteraceae) - with common name Ajgandha, Ghandhari, Sahadevi - is an annual herb with a long history of traditional medicinal used in many countries in the world, especially in the tropical and subtropical regions [I]. The plant has been used as purgative, febrifuge, treatment of ulcers and wound dressing [2]. In addition to its popular use for skin diseases and wound healing, a decoction of the plant is taken to treat diarrohea and to relieve pain associated with the navel in children [3].

The secondary metabolites of A. conyzoides include flavonoids, alkaloids, coumarins, essential oils and tannins. Many of these are biologically active [4]. These compounds have been shown to affect insect development, as anti juvenile hormones, resulting in sterile adults [5]. The research was carried out on $A$. conyzoides leaves in a search for new botanicals possessing good biological activity.

\section{Extraction and Isolation:}

\section{Materials And Methods}

Plants were collected from Landscape, CCSHAU, Hisar, in the month of March -April 2008. The plant material was washed with tap water and separated into different parts (roots, leaves and stems). The dried leaves $(2.5 \mathrm{Kg})$ were chopped into small pieces and put into a round bottom flask $(5 \mathrm{~L})$. The extraction was done by boiling with methanol ( $3 \mathrm{~L}$ ) by heating the flask on a water bath. After six hours, methanol was removed and the leaves were again boiled with methanol. The procedure was repeated thrice. The methanolic extract was concentrated using distillation over a water bath under reduced pressure. The crude extract was sun dried and divided into two parts. One part (250g) was mixed with silica gel (60 - 120 mesh), again dried on a water bath and subjected to silica gel (60 - 120 mesh) column chromatography. The other part (100g) was fractionated with different solvents of increasing polarity viz. hexane, benzene and ethyl acetate. Fractions so obtained were concentrated over a water bath under reduced pressure. The obtained viscous mass was dried in sunlight for several hours and the completely dried material was used for determining the plant growth inhibitory activity against germination of radish seeds.

The elution of the column was done with solvents of increasing polarity. The eluotropic series with increasing polarity comprising of petroleum ether, benzene, ethyl acetate, methanol and their mixtures were used to isolate the compounds. The column chromatography afforded six compounds labeled as L1 - L6. The characterization of compounds was done with the help of their melting point, recorded at the Ganson Electrical melting point, ${ }^{1} \mathrm{HNMR}$ spectra, recorded on Bruker AC-300F $300 \mathrm{MHz}$ NMR spectrometer in $\mathrm{CDCl}_{3}$ and DSMO-d6 using TMS as internal standard, IR spectra recorded on Hitachi 570 infrared spectrophotometer using $\mathrm{KBr}$, and Mass spectra, recorded on VG-70S 11-250J GC-MS-DS mass spectrometer. 


\section{Herbicidal Test}

The radish seeds ( Raphanus sativus L.), procured from Kishan Sewa Kendra, CCSHAU Hisar, were surface sterilized in $95 \%$ ethanol for $15 \mathrm{~s}$. Ten seeds were sown in Petri plates of $90 \mathrm{~mm}$ diameter containing two layers of ordinary filter papers. Seven $\mathrm{ml}$ of test solutions of different fractions of varying concentrations $(500,1000,2000 \mathrm{ppm})$ was poured in each Petri plate. The stock test solution was prepared by dissolving the desired amount of dried fraction in $1 \mathrm{ml}$ of ethanol and then mixing with $30 \mathrm{ml}$ of distilled water. The different concentrations of fraction were prepared from stock solution. A mixture of distilled water: ethanol (30:1, $7 \mathrm{ml})$ was taken as control. Three replicates of each concentration were taken. The radish seeds were allowed to germinate at the $25{ }^{\circ} \mathrm{C}$ in the incubator with $12 \mathrm{~h}$ of photoperiod. After $120 \mathrm{~h}$, the number of seeds germinated in each Petri plate was counted and percent seed germination inhibition values were calculated [6].

\section{Compound L1 (Tritriacontane, 1 )}

\section{Experimental Section}

The compound was obtained on elution with pure hexane, $25 \mathrm{mg}$, m.p. $71{ }^{\circ} \mathrm{C}$ (literature m.p. $71.8{ }^{\circ} \mathrm{C}$ ) [7]. IR $(\mathrm{KBr}) v_{\max }\left(\mathrm{cm}^{-1}\right): 722,802,866,1023,1097,1261,1378,1466,2848,2917 ;{ }^{1} \mathbf{H}-\mathbf{N M R}\left(\boldsymbol{\delta}, \mathbf{C D C l}_{3}\right): 1.12-$ $1.40\left(62 \mathrm{H}, \mathrm{br}, 31 \mathrm{x}-\mathrm{CH}_{2}-\right), 0.82\left(6 \mathrm{H}, \mathrm{t}, J 7.5 \mathrm{~Hz}, 2 \mathrm{x}-\mathrm{CH}_{3}\right) ; \mathbf{M S}\left(\mathbf{m} / \mathbf{z}\right.$, relative intensity): $464\left(\left(\mathrm{M}^{+}, 4.79\right), 436\right.$ (11.98), 414 (11.98), 412 (34.73) 408 (23.95), 380 (82.03), 352 (100), 330 (53.29), 202 (38.32), 174 (17.36).

\section{Compound L2 (Henitriacontane, 2)}

It was obtained on elution with pure hexane as white waxy solid, $20 \mathrm{mg}$, m.p. $70{ }^{\circ} \mathrm{C}$, (literature m.p. 68 $\left.{ }^{\circ} \mathrm{C}\right)$ [7]. It was crystallized out from benzene. IR (KBr) $v_{\max }\left(\mathrm{cm}^{-1}\right): 669,760,1021,1096,1215,1260,1377$, 1464, 2849, 2917; ${ }^{\mathbf{1}} \mathbf{H}-\mathbf{N M R}\left(\boldsymbol{\delta}, \mathbf{C D C l}_{3}\right){ }^{\vdots} 1.22-1.44\left(58 \mathrm{H}, \mathrm{m}, 29 \mathrm{x}-\mathrm{CH}_{2}-\right), 0.84$ ( 6H, t, J 7.5 Hz, 2x -CH3); MS $\left(\mathbf{m} / \mathbf{z}\right.$, relative intensity); $436\left(\left(\mathrm{M}^{+}, 3.38\right), 419\right.$ (12.57), 414 (19.16), 412 (59.88) 408 (31.14), 380 (73.65), 352 (96.41), 330 (100), 310 (7.78), 202 (15.57), 174 (20.36).

\section{Compound L3 (23-Pentatetraacontanone, 3)}

The elution by benzene: hexane (1:9) afforded this compound as a white powder, $20 \mathrm{mg}, \mathrm{m} . \mathrm{p} ., 80^{\circ} \mathrm{C}$. IR (KBr) $v_{\max }\left(\mathrm{cm}^{-1}\right): 700,799,865,1021,1260,1410,1715,2847,2915,2962 ;{ }^{1} \mathbf{H}-\mathbf{N M R}\left(\boldsymbol{\delta}, \mathbf{C D C l}_{3}\right): 2.35$ $\left(4 \mathrm{H}, \mathrm{t}, J 7.0 \mathrm{~Hz}, 2 \mathrm{x}-\mathrm{CH}_{2}-\mathrm{CHO}-\right), 1.54\left(4 \mathrm{H}, \mathrm{m}, 2 \mathrm{x}-\mathbf{C H}_{2}-\mathrm{CH}_{2}-\mathrm{CHO}-\right), 1.20\left(76 \mathrm{H}, \mathrm{br}, 38 \mathrm{x}-\mathrm{CH}_{2}-\right), 0.78(6 \mathrm{H}, \mathrm{t}, J$ $\left.7.0 \mathrm{~Hz}, 2 \mathrm{x}-\mathrm{CH}_{3}\right) ; \mathrm{MS}\left(\mathbf{m} / \mathbf{z}\right.$, relative intensity): $646\left(\mathrm{M}^{+}\right), 618,582,558,542,510,482,458(6.59), 457$ (17.96), 436 (8.98), 412 (18.56), 408 (31.14), 380 (84.43), 352 (100), 330 (39.52), 202 (23.95), 174 (26.95).

\section{Compound L4 (3,4, -Seco-lup- 20 (29)-en-3-OMe, 4)}

The compound was obtained on elution with benzene: hexane (1:3), crystallized out from ethyl acetate, $25 \mathrm{mg}$, m.p. $274{ }^{\circ} \mathrm{C}$, (literature m. p. $275^{\circ} \mathrm{C}$ ) [8]. The Liebermann-Burchard reaction for this compound hinted the presence of terpenoid. IR $(\mathrm{KBr}) v_{\max }\left(\mathrm{cm}^{-1}\right): 800,1020,1094,1261,1378,1462,1734,2848,2917,2960$; ${ }^{1} \mathbf{H}-\mathbf{N M R}\left(\boldsymbol{\delta}, \mathbf{C D C l}_{3}\right): 4.60(2 \mathrm{H}, \mathrm{m}, \mathrm{H}-20), 3.70\left(3 \mathrm{H}, \mathrm{s},-\mathrm{O}-\mathrm{CH}_{3}\right), 2.40(2 \mathrm{H}, \mathrm{t}, \mathrm{J} 7.0 \mathrm{~Hz},-\mathrm{CH}-\mathrm{CO}-), 1.25-1.59$ $\left(27 \mathrm{H}, \mathrm{m}, 1 \mathrm{x}-\mathrm{CH}_{3}, 9 \mathrm{x}-\mathrm{CH}_{2^{-}}, 6 \mathrm{x}>\mathrm{CH}-, 0.78-1.02\left(18 \mathrm{H}, \mathrm{m}, 6 \mathrm{x}-\mathrm{CH}_{3}\right) ; \mathrm{MS}\left(\mathbf{m} / \mathbf{z}\right.\right.$, relative intensity):456 $\left(\mathrm{M}^{+}\right.$, 5.39), 419 (17.36), 414 (25.15), 412 (77.24), 380 (71.86), 352 (100), 330 (44.91), 296 (13.77), 202 (19.16).

\section{Compound L5 ( $3^{\circ}$ Butyl triacosanoate, 5)}

It was obtained on elution with benzene-hexane (1:3) and crystallized out in acetone, 24 mg, m.p. 80 ${ }^{\circ} \mathrm{C}$. IR $(\mathrm{KBr}) v_{\max }\left(\mathrm{cm}^{-1}\right): 702,800,864,1020,1092,1260,1413,1462,1734,2847,2915:{ }^{1} \mathbf{H}-\mathbf{N M R}(\boldsymbol{\delta}$, $\left.\mathbf{C D C l}_{3}\right): 0.80-2.00(51 \mathrm{H}, \mathrm{m}, 21 \mathrm{x}-\mathrm{CH} 2-, 3 \mathrm{x}-\mathrm{CH} 3), 0.88(3 \mathrm{H}, \mathrm{t}, J 7.0 \mathrm{~Hz}, 1 \mathrm{x}-\mathrm{CH} 3)$; MS (m/z, relative intensity): $412\left(\mathrm{M}^{+}, 4.78\right), 408$ (80.24), 380 (81.44), 352 (100), 330 (56.89), 300 (10.18), 202 (22.15), 174 (20.96).

\section{Compound L6 (Methyltetracosanoate, 6)}

The compound was obtained on elution with pure benzene and crystallized out in methanol, $24 \mathrm{mg}$, m.p. $57^{\circ} \mathrm{C}$, (literature m.p. $59.5^{\circ} \mathrm{C}$ ) [7]. IR (KBr) $v_{\max }\left(\mathrm{cm}^{-1}\right): 722,802,1063,1261,1466,1733,2848,2918$ : ${ }^{1} \mathbf{H}-\mathbf{N M R}\left(\boldsymbol{\delta}, \mathbf{C D C l}_{3}\right): 3.50\left(3 \mathrm{H}, \mathrm{s},-\mathrm{COOCH}_{3}\right), 2.20\left(2 \mathrm{H}, \mathrm{br},-\mathrm{CH}_{2}-\mathrm{CH}_{2} \mathrm{COOMe}\right), 1.24-2.00\left(40 \mathrm{H}, \mathrm{m}, 20 \mathrm{x}-\mathrm{CH}_{2}-\right.$ ), $0.86\left(3 \mathrm{H}, \mathrm{t}, J 7.5 \mathrm{~Hz}, 1 \mathrm{x}-\mathrm{CH}_{3}\right)$; $\mathbf{M S}$ (m/z, relative intensity): $382\left(\mathrm{M}^{+}\right), 174$ (50.90), $202(20.36), 214(9.58)$, 295 (8.89), 353 (50.90), 381 (41.32).

\section{Compound L1 (Tritriacontane, 1)}

\section{Result And Discussion}

The compound was afforded on elution with pure hexane as waxy solid, $20 \mathrm{mg}$, m.p. $71{ }^{\circ} \mathrm{C}$ (literature m.p. $71.8^{\circ} \mathrm{C}$ ) [7]. The IR of the compound indicated the absence of functional groups like $\mathrm{CO}$ and $\mathrm{OH}$. The MS of the compound showed its molecular weight to be 464 and the molecular formula to be $\mathrm{C}_{33} \mathrm{H}_{68}$. The ${ }^{1} \mathrm{H}$ NMR 
of the compound in $\mathrm{CDCl}_{3}$ showed a triplet $(\mathrm{J} 7.5 \mathrm{~Hz})$ at $\delta 0.82$, integrating to six protons, which could be due to two terminal methyls. A multiple was observed in the range $\delta 1.12-1.40$, for sixty two protons, which represented thirty one methylenes. This data hinted the compound to be tritriacontane. There is an identity between observed data and literature data [7] for tritriacontane. The compound L1 was therefore confirmed to be tritriacontane (1). This is the first report of characterization and isolation of tritriacontane from A. conyzoides leaves.

$$
\mathrm{CH}_{3}-\left(\mathrm{CH}_{2}\right)_{31}-\mathrm{CH}_{3}
$$

1.

\section{Compound L2 (Henitriacontane, 2)}

The compound was afforded on elution with pure hexane as waxy solid, $20 \mathrm{mg}$, m.p. $70{ }^{\circ} \mathrm{C}$ (literature m.p. $68{ }^{\circ} \mathrm{C}$ ) [7]. The IR of the compound indicated the absence of functional groups like $\mathrm{CO}$ and $\mathrm{OH}$. The MS of the compound showed its molecular weight to be 436 and the molecular formula to be $\mathrm{C}_{31} \mathrm{H}_{64}$. The ${ }^{1} \mathrm{H}$ NMR of the compound in $\mathrm{CDCl}_{3}$ showed a triplet $(\mathrm{J} 7.5 \mathrm{~Hz})$ at $\delta 0.84$, integrating to six protons, which could be due to two terminal methyls. A multiple was observed in the range $\delta 1.22-1.44$, for fifty eight protons, which represented twenty nine methylenes. This data hinted the compound to be henitriacontane. There is an identity between observed data and literature data for henitriacontane The compound L2 was therefore confirmed to be henitriacontane (2). This is the first report of characterization and isolation of henitriacontane from $A$. conyzoides leaves.

$$
\mathrm{CH}_{3}-\left(\mathrm{CH}_{2}\right)_{29}-\mathrm{CH}_{3}
$$

\section{2.}

\section{Compound L3 (23-Pentatetraacontanone, 3)}

The compound was eluted with ethyl acetate : benzene $(1: 19)$ as white powder $20 \mathrm{mg}$, m.p. $80{ }^{\circ} \mathrm{C}$. The IR spectrum of the compound showed the presence of a carbonyl group $\left(1715 \mathrm{~cm}^{-1}\right)$. The $\mathrm{M}^{+}(646)$ of the compound was observed that is the molecular mass of the compound. The ${ }^{1} \mathrm{H}-\mathrm{NMR}$ of the compound in $\mathrm{CDCl}_{3}$, showed no signal in the aromatic region indicating the alphabetic nature of the compound. A triplet $(J 7.0 \mathrm{~Hz})$ at $\delta$ 2.35 , for four protons could be due to methylenes $\alpha$ to keto group. A multiplet at $\delta 1.54$, indicating four protons, was attributable to methylenes $\beta$ to keto group. A broad signal at $\delta 1.20$, representing seventy-six protons, was assigned to thirtyeight methylenes. A triplet $(J 7.0 \mathrm{~Hz})$ centered at $\delta 0.78$, integrating to six protons, was assigned to an aliphatic terminal methyl group. Thus the compound could be characterized as 23-Pentatetraacontanone (3). The MS fragmentation pattern lends further support to the proposed structure. A comparison of data on this compound, $\mathrm{P}$ with the literature data for 23Pentatetraacontanone [9], confirmed that identity of the compound as 23-Pentatetraacontanone (3). The compound is first reported from this plant.

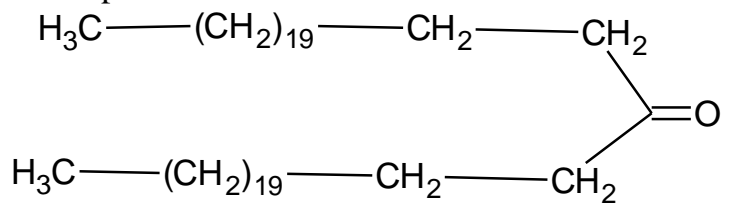

\section{3}

Compound L4 (3,4, -Seco-lup- 20 (29)-en-3-OMe, 4)

The compound was obtained on elution with benzene: hexane (1:3), crystallized out from ethyl acetate, $25 \mathrm{mg}$, m.p. $274{ }^{\circ} \mathrm{C}$, (literature m. p. $274{ }^{\circ} \mathrm{C}$ ) [8]. The Librman-Burchard reaction for this compound gives brown colour, hinted the presence of terpenoid. The IR of the compound indicated the presence of -CO- group $\left(1734 \mathrm{~cm}^{-1}\right)$. The GC-MS of the compound suggested its molecular mass to be (456). The ${ }^{1} \mathrm{H}-\mathrm{NMR}$ of compound in $\mathrm{CDCl}_{3}$ showed a multiplet for two olefinic protons at $\delta$ 4.60. A singlet for three protons was observed at $\delta 3.70$ which could be due to $-\mathrm{OCH}_{3}$ group. There was a triplet for two protons at $\delta 2.40$ which could be due to a methylene $\alpha$ to -CO- group. There was a multiplet in the range $\delta 1.25-\delta 1.59$ for twenty seven protons could be due to one methyl, nine methylenes and six methaine. A multiplet in the range $\delta 0.78-1.02$ for 18 protons represented 6 methyls. This data suggested the compound L4 to be (3,4, -Seco-lup- 20 (29)-en-3$\mathrm{OMe})(4)$.

There was a complete consistency in the observed data for compound L4 with literature data for Compound (3,4, -Seco-lup- 20 (29) -en-3-OMe) confirming the identities of the former to be the later. 


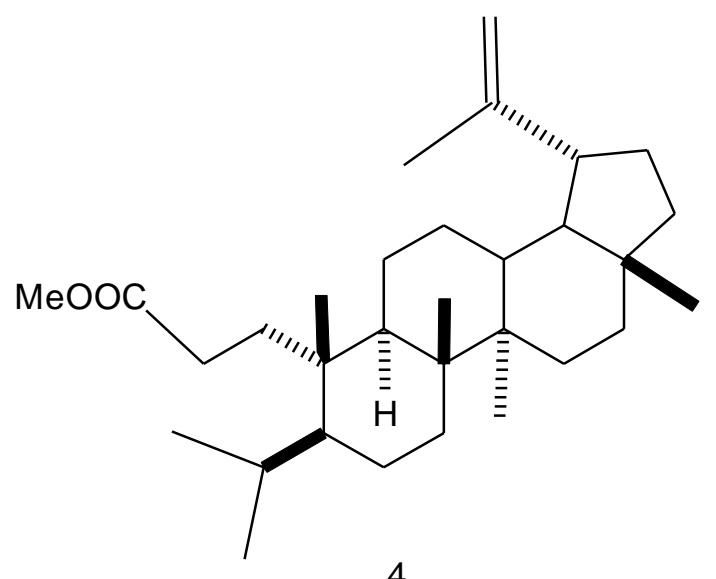

Compound L5 ( $3^{\circ}$ Butyl triacosanoate, 5$)$

It was obtained on elution with benzene : hexane (1:3) as waxy solid, $24 \mathrm{mg}$. It crystallized out from benzene as a white solid, m.p. $80{ }^{\circ} \mathrm{C}$. The IR of the compound indicated the presence of $\mathrm{CO}$ group $\left(1734 \mathrm{~cm}^{-1}\right)$. The $\mathrm{M}^{+}(410)$ of the compound was not observed but $\mathrm{M}^{+}+2$ (412) was observed. The elemental analysis of the compound also suggested its molecular mass (410) and molecular formula $\mathrm{C}_{27} \mathrm{H}_{54} \mathrm{O}_{2}$. The ${ }^{1} \mathrm{H}$ NMR of the compound in $\mathrm{CDCl}_{3}$ depicted a multiplet at the range $\delta 0.80-2.00$, integrating fifty-one protons, indicating the presence of three methyl groups attached to $3^{\circ}$ carbon and twenty-one methylene. A triplet $(J 7.5 \mathrm{~Hz})$ was observed at $\delta 0.88$, integrating to three protons, hinting a terminal methyl group. This data suggested the compound to be $3^{\circ}$ Butyl triacosanoate (5). After a survey of the literature it was reveled that this is a hitherto unreported compound.

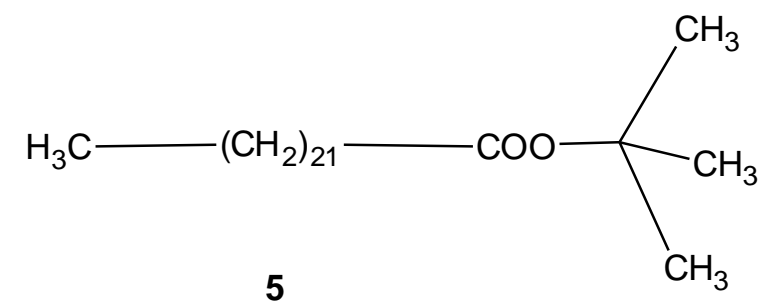

\section{Compound L6 (Methyltetracosanoate, 6)}

This compound was obtained on elution with benzene: hexane (1:1). It crystallized out from methanol as a white solid, m.p. $57^{\circ} \mathrm{C}$, (literature m.p. $59.5^{\circ} \mathrm{C}$ ) [7], $24 \mathrm{mg}$. The IR of the compound indicated the presence CO group $\left(1733 \mathrm{~cm}^{-1}\right)$. The MS of the compound suggested its molecular mass to be 382 and the molecular formula to be $\mathrm{C}_{25} \mathrm{H}_{50} \mathrm{O}_{2}$. The ${ }^{1} \mathrm{H}$ NMR of the compound in $\mathrm{CDCl}_{3}$ depicted a singlet at $\delta 3.50$, integrating to three protons, indicating the presence of an -OMe group. There was a broad signal at $\delta 2.20$, integrating to two protons, hinting a methylene group $\alpha$ to a carbonyl group. There was a multiplet in the range of $\delta 1.24-2.00$ for forty two protons, representing twenty one methylenes. A triplet $(J 7.5 \mathrm{~Hz})$ was observed at $\delta 0.86$, integrating to three protons, hinting a terminal methyl group. This data suggested the compound to be methyl tetracosanoate. A comparison of the data of the compound L6 with the literature data [7], for methyl tetracosanoate, confirmed the identity of the compound as methyl tetracosanoate (6). It is the first report of characterization and isolation methyl tetracosanoate from A. conyzoides leaves.

$$
\mathrm{CH}_{3}-\left(\mathrm{CH}_{2}\right)_{21}-\mathrm{CH}_{2} \mathrm{COOCH}_{3}
$$

6.

\section{PLANT GROWTH INHIBITORY ACTIVITY}

The Methanolic extract and four different fractions (hexane, benzene, ethyl acetate and methanol) of the leaves of A. conyzoides were tested for their plant growth inhibitory activity against the germination of seeds of radish at 100, 500, 1000, 1500 and $2000 \mu \mathrm{g} / \mathrm{ml}$ concentrations. The data - presented in Table 1 - revealed that maximum inhibition i.e. $60 \%$ was shown by methanolic extract followed by hexane fraction i.e. $50 \%$ at $2000 \mu \mathrm{g} / \mathrm{ml}$. The benzene, ethyl acetate and methanol fractions showed maximum inhibition of seeds germination i.e. $10 \%, 23.4 \%$, and $13.4 \%$ at $2000 \mu \mathrm{g} / \mathrm{ml}$. The seeds of radish were found sensitive to germinate at $2000 \mu \mathrm{g} / \mathrm{ml}$ concentration of methanolic extract followed by the hexane fraction of the leaves. The seeds were also found sensitive to germinate at $1500 \mu \mathrm{g} / \mathrm{ml}$ concentrations of hexane, ethyl acetate and methanol fractions of leaves. 
In all the tested extracts and fractions of roots, leaves and stems of $A$. conyzoides, the methanolic extract of the leaves showed significant inhibition i.e. $60 \%$ at $2000 \mu \mathrm{g} / \mathrm{ml}$ followed by the hexane fraction of the leaves and methanolic extract of roots i.e. $50 \%$. All other fractions and extracts were found less active against the germination of seeds of radish.

Table 1: Effect of different extract / fractions of Ageratum conyzoides leaves on germination of radish seeds, $120 \mathrm{~h}$ of sowing

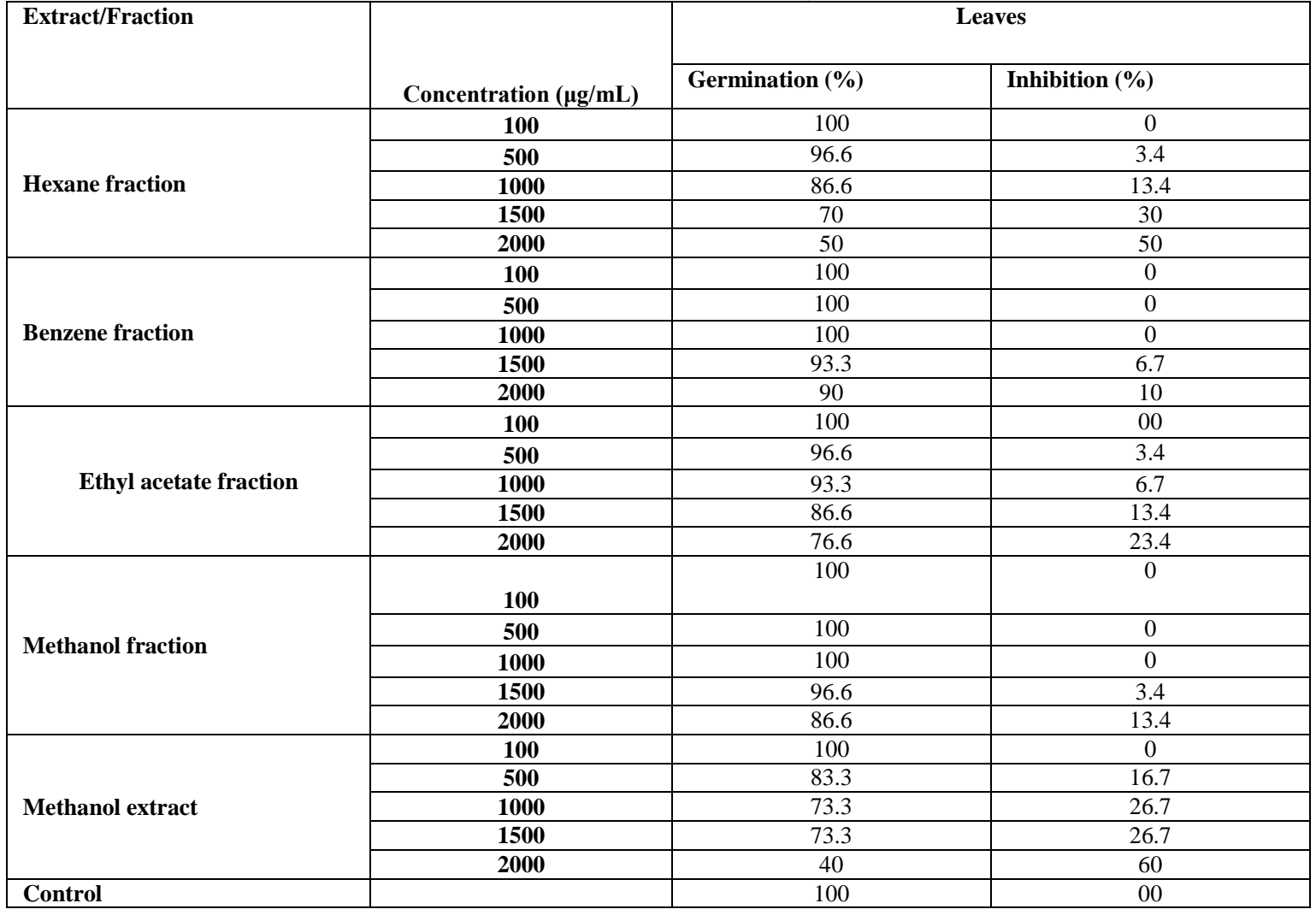

\section{References}

[1]. A. Anonymous, The wealth of India (NISCOM, New Delhi, India, First Supplement Series, 2000).

[2]. T.S. Githens, Drug Plants of Africa, 8 (African Handbooks, Pretoria, South Africa, 1948) 59.

[3]. A. L. Okunade, A Review: A. conyzoides L., Fitoterapia, 273, 2002, 1-16

[4]. G.P. Widod, F. L. Sukandar, Sukrasno and I. K. Adnyana, A coumarin from Ageratum leaves (Ageratum conyzoides), International Journal of pharmacology; 4 (1), 2008, 56-59.

[5]. N. Borthakur and A.K.S. Baruah, Search for precocenes in Ageratum conyzoides Linn. of North-East India, J. Indian Chem. Soc., 64, 1987, 580-581.

[6]. V. D. Feo, L. D. Martino, E. Quaranta and C. Pizza, Isolation of phytotoxic compounds from tree of Heaven (Ailanthus altissima) Swingle), J. Agric. Food Chem., 51, 2003, 1177- 1180.

[7]. J. Buckingham, Dictionary of natural products (Chapman and Hall, London, 1994).

[8]. Sukh Dev, Handbook of Terpenoids, (CRC Press Inc. Boca, Raton, Florida,1989).

[9]. J. Heilbron, A. H. Cook, H.M Bunbuyr. and D.H. Hey (ed). Dictionary of organic compounds (London, Eyre and Spottiswoode, $1965)$. 